\title{
Dissipated Strain Energy of Aluminum Alloy 6061-T6 Induced by Low Cycle Fatigue
}

\author{
Tayeb Kebir ${ }^{*}$, Zine El Abidine Harchouche ${ }^{1}$, Abbes Elmeiche ${ }^{2}$, Mohamed Benguediab ${ }^{1}$ \\ ${ }^{1}$ Laboratory of Materials and Systems Reactive, Department of Mechanical Engineering, Faculty of Technology, University of \\ Sidi Bel Abbes 22000, Algeria \\ ${ }^{2}$ Laboratory Mechanics of Structures and Solids, Department of Mechanical Engineering, Faculty of Technology, University \\ of Sidi Bel Abbes 22000, Algeria
}

Corresponding Author Email: kebirtayeb@live.fr

https://doi.org/10.18280/acsm.430508

Received: 16 June 2019

Accepted: 13 August 2019

\section{Keywords:}

dissipated strain energy, low cycle fatigue, imposed plastic strain, hysteresis loop, alloy 6061-T6

\begin{abstract}
It is extremely difficult to measure the strain energy dissipated in each loading cycle, especially when the material suffers from low cycle fatigue under plastic strain. This paper attempts to simulate the dissipated strain energy of aluminum alloy 6061-T6 induced by the low cycle fatigue under an imposed plastic strain. Hence, an ANSYS numerical simulation was performed on the low cycle fatigue permitting to generate the hysteresis loops at failure of each cyclic plastic strain imposed on aluminum alloy 6061-T6. The area of the hysteresis loops was adopted to measure the dissipated strain energy. The simulation results show that the energy dissipated during loading gives a good measure of a material's residual strength, stiffness and capacity to resist further loading.
\end{abstract}

\section{INTRODUCTION}

The tests of low cycle fatigue at a plastic strain imposed have been used to modeling the hysteresis loops and subject of several studies in the literature [1-4]. Investigation of the low cycle fatigue of materials focused on changes in the dislocation microstructures of each cycle, residual strain after initial unloading under Bouchenger effect, stiffness of each cycle and energy dissipated as a result of cycling. These properties have a large impact on a structure's performance [5]. Also, it is now clear that energy is dissipated in fatigue because of plastic deformation, which gives rise to the changes in material structure, such as phase changes, development of residual stress, translation of dislocations, and the creation and/or enlargement of internal surfaces such as voids and cracks [3].

Thus, when the hysteresis loops generated, the area of these hysteresis can be presenting the stain energy dissipated [6-7]. The enclosed area in the loop is the strain energy per unit volume released as heat in each loading cycle [8]. Therefore, during loading, dissipated strain energy is increased significantly, in the unloading test, the elastic strain energy is released at the stress drop point, while the dissipated strain energy increases sharply [9-10]. However, the energy dissipation process is associated with the entire process of material deformation, thus resulting in material failure $[9,11]$.

The adoption point of view of energy quantities, if they are well chosen, constitutes an indicator allow quantifying the microstructure irreversibility which will have repercussions on the macroscopic properties [12]. The existence of different energy quantities is related to the strain energy is not completely dissipated in cyclic loading, a part; called energy stocked, remain in material. The energy stocked is linked to the multiplication of defect in material such as dislocations. As small crack of fatigue is often due to the multiplication and organization of dislocations, some studies have attempted to use energy stocked to characterize fatigue damage of materials. For example, the works of Ref. [13] are showed a correlation between the energy stocked and the accumulation of damage. Furthermore, the magnitude of the stored strain energy is not characterized fully by the dislocation density and likely depends on dislocation arrangements and the resultant patterns developed as a result of cyclic strain accommodation [12, 13].

The Wohler curve is based on the estimation of the endurance limit determined by statistical methods that prove to be long and expensive for industrial applications. Also, other approaches are based on energy dissipated have been developed to determine this limit $[10,14,15]$. The correlation between dissipated energy and the endurance limit remain poorly understood [16]. In addition, a strain energy based fatigue damage model is proposed which uses the strain energy from applied loads and the strain energy of dislocations to calculate stress-life, strain-life, and fatigue crack growth rates $[17,18]$.

The purpose of this work is to simulate the low cycle fatigue at a plastic strain imposed and to determine the strain energy dissipated from area of the hysteresis loops generated and can be observed horizontal asymptote energy in curve of Energy-Number of cycle, as similarly of endurance limit, using the aluminum alloy 6061-T6. The simulation has been released by the ANSYS code.

\section{FINITE ELEMENT MODELING}

Experimental measurements are often too expensive and time-consuming especially when components are subjected to long cyclic loading histories in service. Therefore, finite element analysis predictions have been widely used by 
researchers for evaluating the different models used for low cycle fatigue $[1,12,19]$.

For the low cycle fatigue testing is used a smooth cylindrical specimen subjected to uniaxial forces, done according to the standard test E606 [20], as presented in Figure 1.

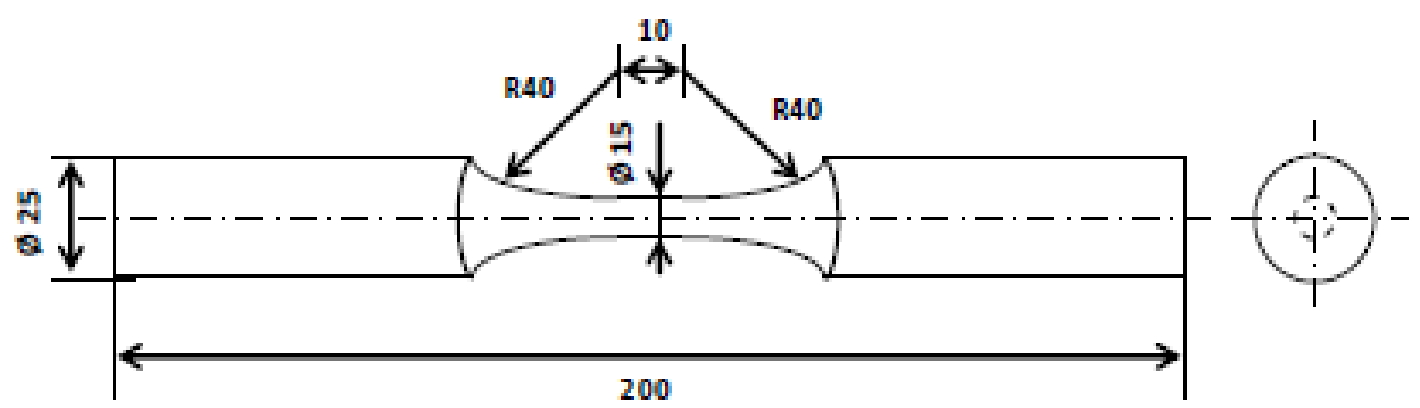

Figure 1. Geometry and dimensions of the specimens used in the strain-controlled fatigue tests (Dimensions in mm)

The material studied is aluminum alloy 6061-T6 for which static and cyclic mechanical properties are obtained by Brammer, Ambriz and Jaramillo [21, 22], shown in Table 1. This material has great importance in the technology industry especially in the construction of a transport aircraft that is due to the high mechanical strength and good corrosion resistance and high hardness.

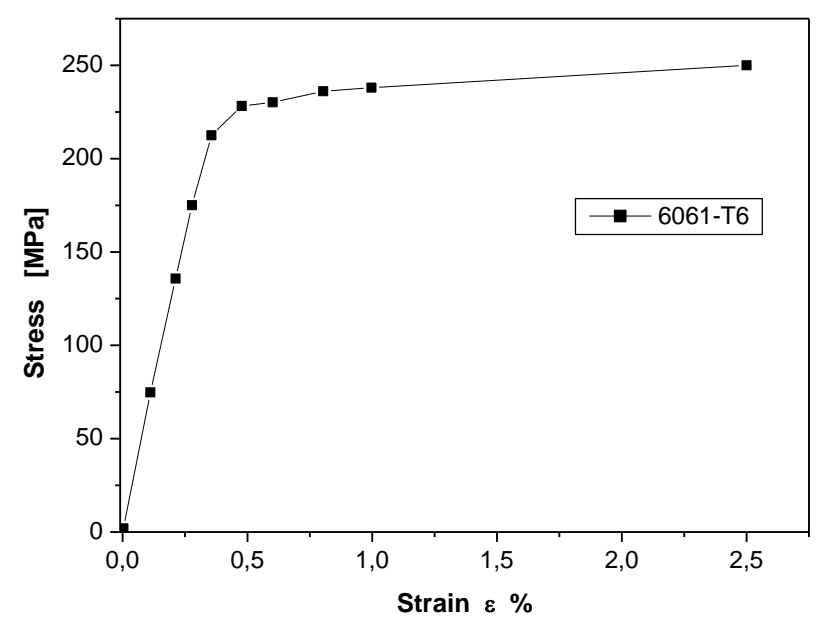

Figure 2. Cyclic stress-strain at ratio $\mathrm{R}=-1$

Table 1. Static and cyclic mechanical properties of 6061-T6

\begin{tabular}{|c|c|}
\hline Young's modulus $\boldsymbol{E}(\mathbf{G P a})$ & 67.8 \\
\hline Poisson's ratio $\boldsymbol{v}$ & 0.3 \\
\hline Yield strength $\boldsymbol{\sigma}_{\boldsymbol{e}}(\mathbf{M P a})$ & 279 \\
\hline Ultimate tensile strength $\boldsymbol{\sigma}_{\boldsymbol{u}}(\mathrm{MPa})$ & 310 \\
\hline Elongation $\boldsymbol{\varepsilon}_{\boldsymbol{f}}(\boldsymbol{\%})$ & 14.0 \\
\hline Fatigue strength coefficient $\left.\boldsymbol{\sigma}_{\boldsymbol{f}} \mathbf{( M P a}\right)$ & 705 \\
\hline Fatigue ductility coefficient $\boldsymbol{\varepsilon}_{\boldsymbol{f}}$ & 2.40 \\
\hline Fatigue strength exponent $\boldsymbol{b}$ & -0.11 \\
\hline Fatigue ductility exponent $\boldsymbol{c}$ & -0.98 \\
\hline Hardening coefficient $\boldsymbol{K}^{\prime}(\mathbf{M P a})$ & 502.8 \\
\hline Hardening exponent $\boldsymbol{n}^{\prime}$ & 0.0737 \\
\hline
\end{tabular}

The simulation of the cyclic behavior at different imposed strain levels is carried out with a stress ratio $\mathrm{R}=-1$. The procedure of this simulation is to set the test specimen on one side and cyclically loaded on the other side by imposed displacement amplitude $(\Delta \mathrm{L})$ at a frequency of $2 \mathrm{~Hz}$ as shown in Figure 2. The values of plastic displacement amplitude $(\Delta \mathrm{L})$ can be determined by relation $\Delta \mathrm{L}=\varepsilon$. $\mathrm{L}$, where, $(\varepsilon)$ is strain and (L) its initial length of test specimen equal $200 \mathrm{~mm}$.
For tested this alloy a series of low cycle fatigue simulations at imposed plastic strain amplitude were carried out for different levels according to ASTM E606 standard test [20] as shown in Figure 3. Also, the chosen values of plastic strain imposed that is according to the work experimental [23] as shown in Table 3.

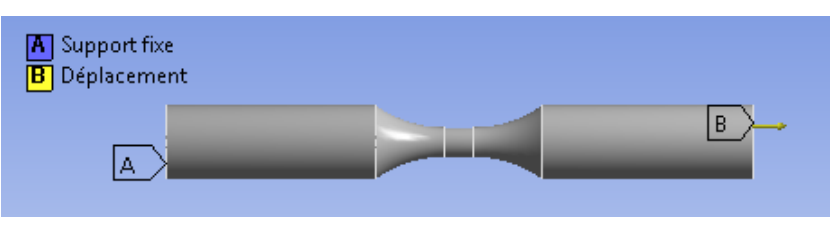

Figure 3. Displacement applied in test specimen

Table 2. Cyclic plastic strain imposed

\begin{tabular}{|c|c|c|c|c|c|}
\hline Material & \multicolumn{5}{|c|}{ Plastic strain imposed in \%/ } \\
\hline $6061-\mathrm{T} 6$ & 0.4 & 0.5 & 0.6 & 0.7 & 1.0 \\
\hline
\end{tabular}

The mesh used is of type Solid185 with 8 nodes having three degrees of freedom at each node which makes possible to visualize the deformations in three directions. The convergence has been checked as shown in Figure 4. The model contains 157329 nodes and 37440 elements.

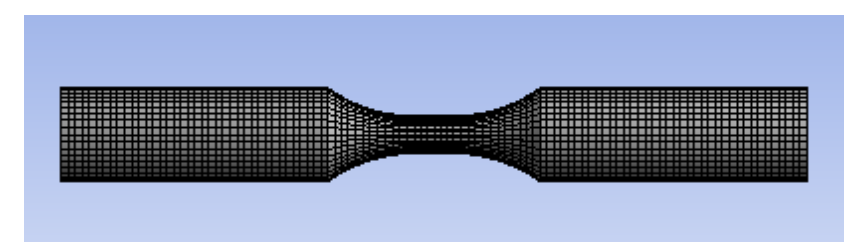

Figure 4. Test specimen meshing

\section{RESULTS AND DISCUSSIONS}

The present work constitutes a numerical simulation of low cycle fatigue permitting to generate the hysteresis loops at failure of each cyclic plastic strain imposed of aluminum alloy 6061-T6, using the Software ANSYS. The area of these hysteresis loops facilitated us to measure the strain energy dissipated.

The Figure 5 shows the life time obtained by one simulation to low cycle fatigue for $0.5 \%$ controlled cyclic plastic strain in aluminum alloy 6061-T6. 
The stabilized hysteresis loops for each level of cyclic plastic strain imposed for the alloy studied are shown in Figure 6. However, the results (Figure 5a) obtained for the 6061-T6 alloy are explained the simulation hysteresis loops showed good agreement with experimental results [21]. Also, the Figure $6 \mathrm{~b}$ shows the following stable hysteresis loops, measured at different values of plastic strain amplitude for the same material.

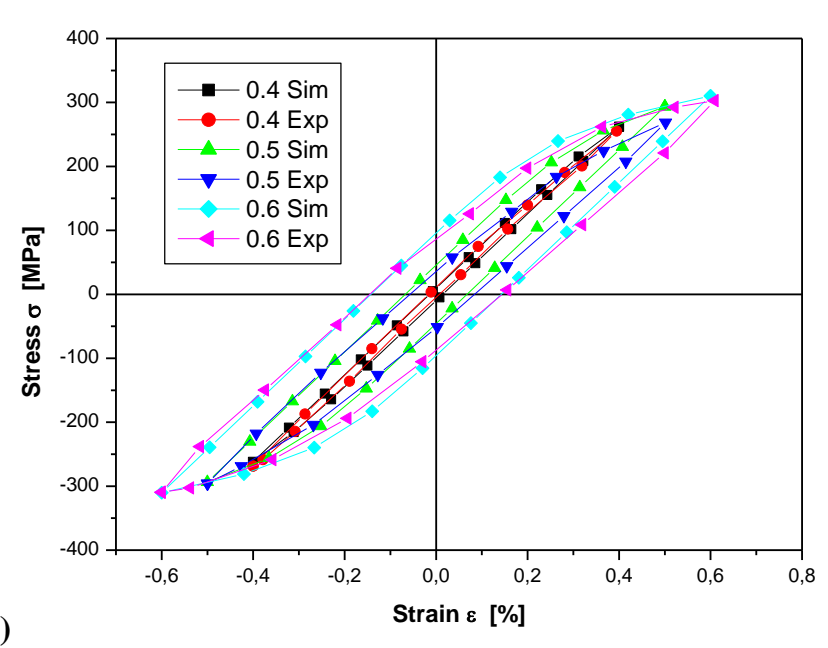

a)

b)

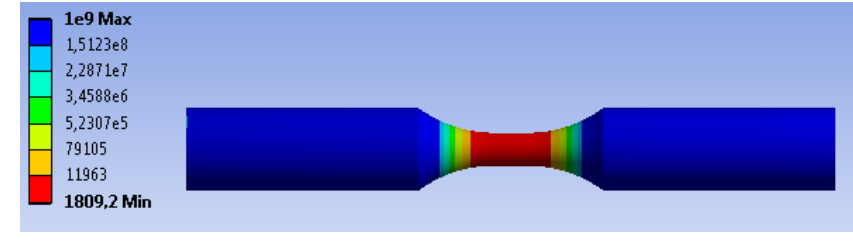

Figure 5. Lifetime obtained by $0.5 \%$ controlled cyclic plastic strain in aluminum alloy 6061-T6

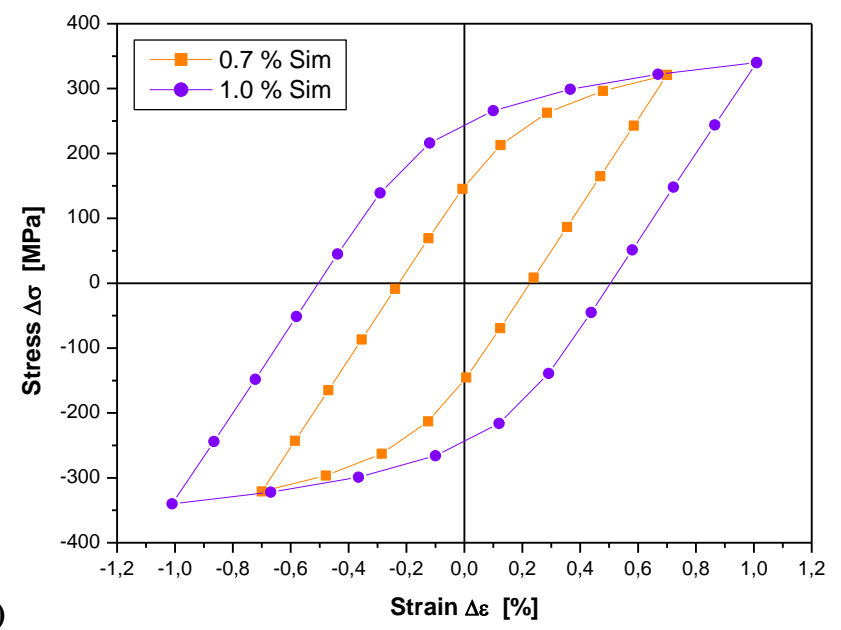

Figure 6. Simulation of hysteresis loops for 6061 T6 aluminum, a) with experimental results [21], b) without experimental results

According to these results and for determined the plastic strain energy dissipated at failure we will make a measurement on each area of these hysteresis loops. The Figure 7 represents the hysteresis loops stabilized at failure for each level cyclic plastic strain imposed of the alloy studied. It can be remarked that the plastic strain imposed increase, increasing the hysteresis loops. The area hatching for each hysteresis loops is measured by Software Origin (Origin is a visualization program that produces graphs and plots intended for direct incorporation in research publications) and shown the total plastic strain energy dissipated at failure which evolve proportionally with plastic strain imposed, this is explained by the material provide a lot of energy stored. However, in the absence of molecular slip and other mechanisms for energy dissipation, this mechanical energy is stored reversibly within the material as strain energy. When the stresses are low enough that the material remains in the elastic range, it's just according to the small area, see Figure 7.

For seems the relationship the strain energy by number of cycles, we are going to design the strain energy obtained by area of these hysteresis loops for each strain imposed versus number of cycles, see Figure 8 . We have remarked that the energy dissipated due to plastic strain imposed increases, increasing the number of cycles [14, 24]. Also, it can be observed that the plastic strain energy attained (or exceed) the value of energy stored, the material suffers a short life. Therefore, the plastic strain energy dissipated evolves inversely with energy stored relative to the number of cycles. It has been suggested by $[12,15]$ and $[4]$ and others that the hysteresis plastic strain energy is related to the number of cycles to failure $N_{f}$ (also to the number of reversals to failure $2 N_{f}$ ) by a power function and can be written as follows:

$$
\Delta W=A\left(2 N_{f}\right)^{\alpha}
$$

where, A and $\alpha$ are material constants, representing material energy absorption capacity and fatigue exponent, respectively. In the case, can be deduce the values of these parameters from a linear regression and are given in Table 4 . These values are comparable to those from the literature for this type of alloy and realized a comparison acceptable.

Table 3. Material constants

\begin{tabular}{|c|c|c|}
\hline 6061-T6 & $\boldsymbol{A}(\boldsymbol{J})$ & $\boldsymbol{\alpha}$ \\
\hline Simulation & 339.1 & -0.064 \\
\hline Experimental [21] & 206.5 & -0.064 \\
\hline
\end{tabular}

The fatigue properties of materials are often described using the fatigue limit or the $\mathrm{S}-\mathrm{N}$ curve (fatigue curve, Wöhler curve). The S-N curve describes the relation between cyclic stress amplitude and number of cycles to failure. The concept of an endurance limit is used in infinite-life or safe stress designs $[15,25]$. Similarly, in this study, the Figure 8 precedent shows a typical $(\Delta \mathrm{W}-\mathrm{N})$ curve (on the horizontal axis the number of cycles to failure and on the vertical axis the strain energy dissipated). A horizontal asymptote can be clearly seen it about the value of $(\mathrm{WD}=50 \mathrm{~J})$ it's called also the limit energy dissipated. Moreover, during loading, the area of hysteresis loops is the strain energy per cycle absorbed by the material. Conversely, the area under the unloading curve is the energy released by the material. In the elastic range, these areas are equal and no net energy is absorbed but if the material is loaded into the plastic range, the energy absorbed exceeds the energy released and the difference is dissipated as heat $[9,14,15]$. Care must be taken when using an energy limit in design applications because it can disappear due to periodic overloads (unpin dislocations), corrosive environments (due to fatigue corrosion interaction) and high temperatures (mobilize dislocations). 

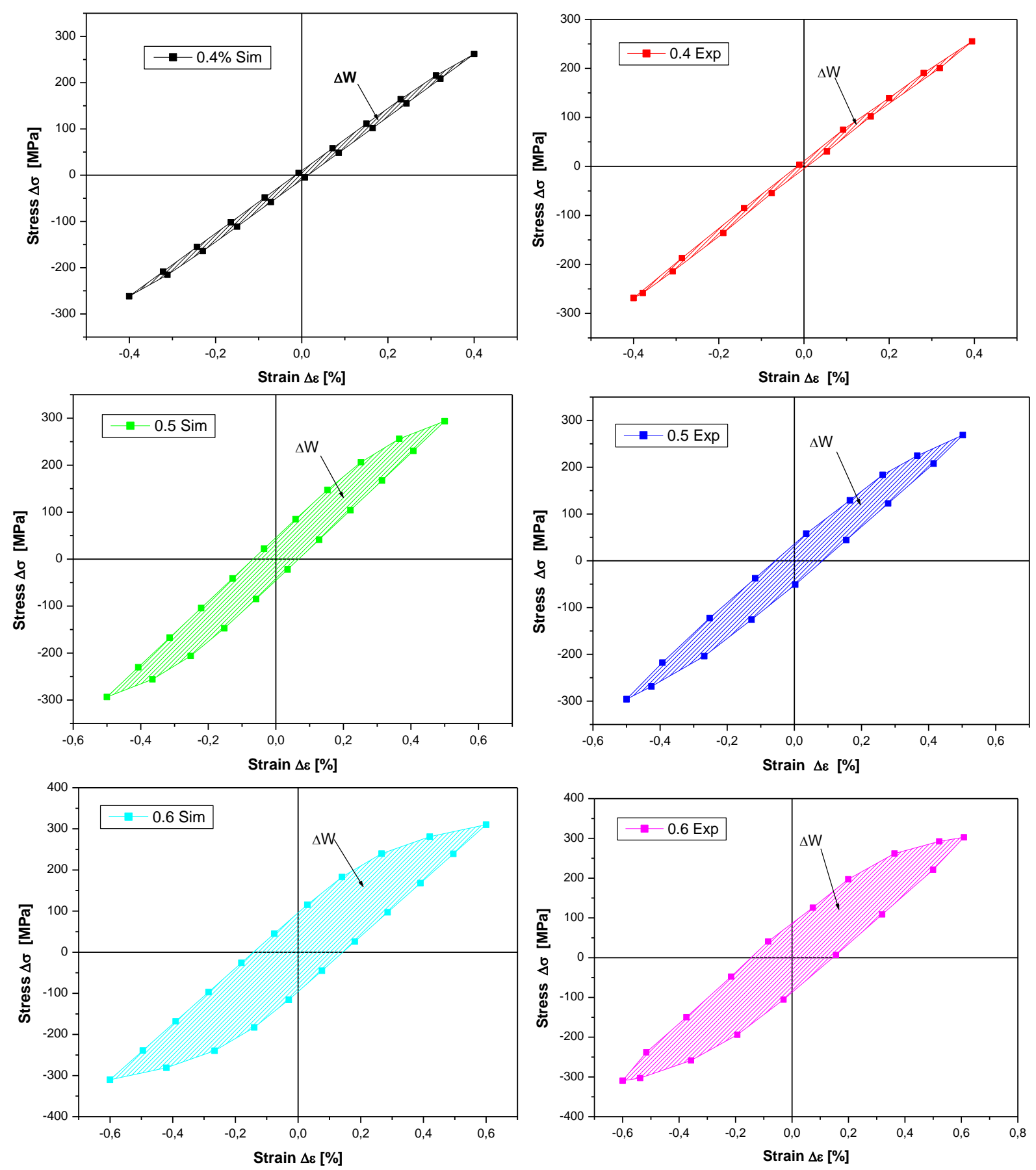

Figure 7. The energy by area of hysteresis loops at failure of each level cyclic plastic strain imposed, (right) simulation results, (left) experimental results [21]

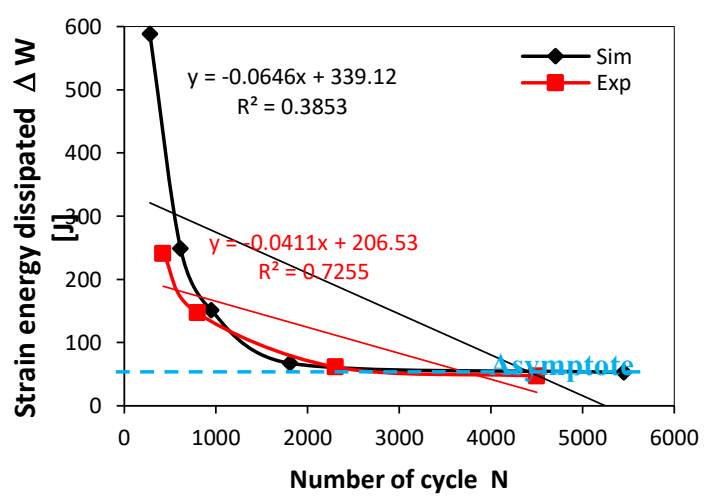

Figure 8. Strain energy dissipated versus number of cycles at failure for area of hysteresis loops

\section{CONCLUSION}

This work of numerical study of the strain energy dissipated due to the low cycle fatigue tests at a cyclic strain imposed for the Aluminum alloy 6061-T6. The main conclusions that were drawn from this study are:

- The strain energy dissipated of a structural element is represented by the area of the hysteresis loops.

- An increase in the imposed strain rate generally leads to an increase in the hysteresis loops,

- The strain energy dissipated due to plastic strain imposed increases, decreasing the number of cycles,

- $\quad$ The strain energy dissipated changes inversely with the energy stored (stored) relative to the number of cycles.

- The strain energy dissipated at failure evolves 
proportionally with the imposed plastic strain, this is explained by the material provides a loss of stored energy,

- The change of strain energy dissipated can be used not only to distinguish the various stages of deformation process, but also to determine the position of the failure point.

Finally, from the results of the simulation, we found that the energy dissipated during loading, as a fraction of the total energy dissipation capacity, gives a good measure of a materials residual strength, stiffness and capacity to resist further loading. The investigation of these properties is meant to give a picture of the expected performance.

\section{REFERENCES}

[1] Kebir, T., Benguediab, M., Miloudi, A., IMAD, A. (2017). Simulation of the cyclic hardening behavior of Aluminum alloys. UPB Sci. Bull. Ser. D Mech. Eng., 79(4): 240-50.

[2] Shen, S., Airey, G.D., Carpenter, S.H., Huang, H. (2006). A dissipated energy approach to fatigue evaluation. Road Mater. Pavement Des., 7(1): 47-69. https://doi.org/10.1080/14680629.2006.9690026.

[3] Ye, D.Y., Wang, Z.L. (2001). A new approach to lowcycle fatigue damage based on exhaustion of static toughness and dissipation of cyclic plastic strain energy during fatigue. Int. J. Fatigue, 23(8): 679-687. https://doi.org/10.1016/S0142-1123(01)00027-5

[4] Abdalla, J.A., Hawileh, R.A., Oudah, F., Abdelrahman, K. (2009). Energy-based prediction of low-cycle fatigue life of BS 460B and BS B500B steel bars. Mater. Des., 30(10): 4405-4413 https://doi.org/10.1016/j.matdes.2009.04.003

[5] Agrawal, R., Uddanwadiker, R., Padole, P. (2014). Low cycle fatigue life prediction. Int. J. Emerg. Eng. Res. Technol., 2(4): 5-15.

[6] Emuakpor, O.S., George, T., Cross, C., Shen, M.H.H. (2010). Hysteresis-loop representation for strain energy calculation and fatigue assessment. J. Strain Anal. Eng. Des., 45(4):

$275-282$ https://doi.org/10.1243/03093247JSA602

[7] Gordon, P.M. (2001). Low cycle fatigue behavior of concrete with recycled concrete aggregates. Thesis of Master of Science in Civil and Environmental Engineering, Faculty of California Polytechnic State University.

[8] Roylance, D. (2001). Stress-Strain curves. Department of Materials Science and Engineering Massachusetts Institute of Technology Cambridge, MA 02139.

[9] Zhang, L., Ren, M., Ma, S., Wang, Z. (2014). Energy dissipation mechanism and damage model of marble failure under two stress paths. Frat. Ed Integrita Strutt., 30: 515-525. https://doi.org/10.3221/IGF-ESIS.30.62

[10] Lefebvre, D., Ellyin, F. (1984). Cyclic response and inelastic strain energy in low cycle fatigue. Int. J. Fatigue, 6(1): 9-15. https://doi.org/10.1016/01421123(84)90003-3

[11] Meneghetti, G., Ricotta, M., Atzori, B. (2015). Experimental evaluation of fatigue damage in two-stage loading tests based on the energy dissipation. Proc. Inst. Mech. Eng. Part C J. Mech. Eng. Sci., 229(7): 12801291. https://doi.org/10.1177/0954406214559112

[12] Mareau, C., Cuillerier, D., Morel, F. (2013). Experimental and numerical study of the evolution of stored and dissipated energies in a medium carbon steel under cyclic loading. Mech. Mater, 60: 93-106. https://doi.org/10.1016/j.mechmat.2013.01.011

[13] Warren, J., Wei, D.Y. (2010). A microscopic stored energy approach to generalize fatigue life stress ratios. Int. J. Fatigue, 32(11): 1853-1861. https://doi.org/10.1016/j.ijfatigue.2010.05.003

[14] Erberik, A., Sucuoglu, H. (2004). Seismic energy dissipation in deteriorating systems through low-cycle fatigue. Earthq. Eng. Struct. Dyn., 33(1): 49-67. https://doi.org/10.1002/eqe.337

[15] Zghal, J. (2016). Etude du comportement en fatigue à grand nombre de cycles d'un acier à haute limite d'élasticité HC360LA : endommagement, plasticité et phénomènes dissipatifs associés. PhD Thesis, Ecole Nationale Supérieure d'Arts et Métiers - ENSAM.

[16] Berthel, B., Chrysochoos, A., Wattrisse, B., Galtier, A. (2008). Infrared image processing for the calorimetric analysis of fatigue phenomena. Exp. Mech., 48(1): 7990. https://doi.org/10.1007/s11340-007-9092-2

[17] Huffman, P.J. (2016). A strain energy based damage model for fatigue crack initiation and growth. Int. J. Fatigue, 88: 197-204. https://doi.org/10.1016/j.ijfatigue.2016.03.032

[18] Huffman, P., J. Ferreira, J.A.F.O. Correia, A.M.P.D.J., Lesiuk, G., Berto, F., Fernández-Canteli, A., Glinka, G. (2017). Fatigue crack propagation prediction of a pressure vessel mild steel based on a strain energy density model. Frat. Ed Integrità Strutt, 42: 170-180. https://doi.org/10.3221/IGF-ESIS.42.18

[19] Korsunsky, A.M., Dini, D., Dunne, F.P.E., Walsh, M.J. (2007). Comparative assessment of dissipated energy and other fatigue criteria. Int. J. Fatigue, 29(9-11): 1990-1995. https://doi.org/10.1016/j.ijfatigue.2007.01.007

[20] ASTM. (2012). Standard test method for straincontrolled fatigue testing. In: Designation: E606/E606M -12, ASTM, 1-16. https://doi.org/10.1520/E0606-04E01

[21] Brammer, A.T. (2013). Experiments and modeling of the effects of heat exposure on fatigue of 6061 and 7075 aluminum alloys. Master of science, University of Alabama.

[22] Ambriz, R.R., Jaramillo, D. (2014). Mechanical behavior of precipitation hardened aluminum alloys welds. InTech, pp. 36-58.

[23] Lipski, A., Mrozinski, S. (2012). The effects of temperature on the strength properties of aluminium alloy 2024-T3. Acta Mech. Autom., 6(3): 62-66.

[24] Giancane, S., Chrysochoos, A., Dattoma, V., Wattrisse, B. (2009). Deformation and dissipated energies for high cycle fatigue of 2024-T3 aluminium alloy. Theor. Appl. Fract. $\quad$ Mech., 52(2): 117-121. https://doi.org/10.1016/j.tafmec.2009.08.004

[25] Pugno, N., Cornetti, P., Carpinteri, A. (2007). New unified laws in fatigue: From the Wöhler's to the Paris' regime. Eng. Fract. Mech., 74(4): 595-601. https://doi.org/10.1016/j.engfracmech.2006.07.009

\section{NOMENCLATURE}

$E$
$K^{\prime}$
$n^{\prime}$

Young's modulus Gpa

Hardening coefficient $\mathrm{MPa}$

Hardening exponent 
Greek symbols

Fatigue ductility coefficient

Strain energy dissipated 